\title{
The Effect of Potential on Surface Characteristic and Corrosion Resistance of Anodic Oxide Film Formed on Commercial Pure Titanium at the Potentiodynamic-Aging Mode
}

\author{
Ling Zhang ${ }^{1}$, Yanqing Duan ${ }^{1}$, Rui Gao ${ }^{1}$, Jianyun Yang ${ }^{1}$, Keyi Wei ${ }^{1}$, Danyu Tang ${ }^{1}$ \\ and Tianlin $\mathrm{Fu}^{2, *}$ \\ 1 R\&D Center of China Tabacco Yunnan Industrial Co., Ltd., Yunnan 650000, China; \\ zhangling@ynzy-tobacco.com (L.Z.); duanyq@ynzy-tobacco.com (Y.D.); zhang-874005@163.com (R.G.); \\ zzy9939@163.com (J.Y.); keyiwei@126.com (K.W.); tangdgirl@126.com (D.T.); \\ 2 School of Materials Science and Engineering, South China University of Technology, \\ Guangzhou 510641, China \\ * Correspondence: msfutl@scut.edu.com; Tel.: +86-135-7046-4399
}

Received: 12 December 2018; Accepted: 18 January 2019; Published: 24 January 2019

\begin{abstract}
Anodic oxidation treatment of commercially pure titanium was carried out at the voltages of $10,30,50 \mathrm{~V}$ in $0.5 \mathrm{M} \mathrm{H}_{2} \mathrm{SO}_{4}$ solution at the potentiodynamic-aging mode so as to obtain the effects of the anodic potential on the surface characteristic and corrosion resistance of the anodic oxide film. The influences of potential on the surface morphology, the roughness, the crystalline behavior, the chemical composition and the corrosion resistance of the anodic oxide films were investigated by using scanning electron microscopy (SEM), atomic force microscope (AFM), Raman spectrum, X-ray diffractometry (XRD), X-ray photoelectron spectroscopy (XPS), potentiodynamic polarization curves and electrode impedance spectroscopy (EIS). The results show that increasing anodic potential at the potentiodynamic-aging mode can significantly enhance thickness, flatness, crystallization, chemical stability, and corrosion resistance of anodic oxide film.
\end{abstract}

Keywords: commercially pure titanium; passive film; surface characteristic; potentiodynamic-aging mode; corrosion resistance

\section{Introduction}

Titanium and its alloys have been extensively used in aerospace, marine engineering, biomedical applications due to their excellent properties [1]. The excellent corrosion resistance of titanium is due to an ultra-thin amorphous film, which grows spontaneously on its surface in air and aqueous environments $\left(\mathrm{Ti}+\mathrm{O}_{2}=\mathrm{TiO}_{2}, \Delta \mathrm{G}_{0}=-888.8 \mathrm{~kJ} \cdot \mathrm{mol}^{-1}\right)$ [2]. This native oxide film can prevent the metal from further reacting with corrosive environments [3]. Unfortunately, these films have many defects, only a few nm in thickness [4]. What is more, according to Hanawa et al. [5], the oxide film formed in air is composed of $\mathrm{Ti}^{4+}, \mathrm{Ti}^{3+}, \mathrm{Ti}^{2+}$ and metallic $\mathrm{Ti}^{0}$. Multivalent $\mathrm{Ti}$ is thermodynamically less favorable than $\mathrm{Ti}^{4+}$. As a result, it can be destroyed easily owing to many reasons, leading to crevice and galvanic corrosion $[4,6]$.

Surface modification methods are extensively applied in improving corrosion resistance of the titanium and its alloys, such as plasma, ion implantation, anodic oxidation treatment, spraying, etc. $[7,8]$. Among them, anodic oxidation treatment is one of the most important surface modification techniques on account of its lower cost and operability [9]. The corrosion resistance of the anodic oxide film depends on its morphology, thickness, chemical composition, and crystallization. In addition, 
these properties can be programmed by using a suitable electrolyte, anodic density, anodic potential, treated time and anodic modes.

Anodic potential may be the most important parameter for the anodic oxide film. Diamanti et al. [1] revealed that high potentials bring about a crystalline structure of the anodic films on titanium, on the contrary, low potentials lead to an amorphous structure. Karambakhsh et al. [10] reported that the thickness was increased by the ascending anodic potential. The crystalline titanium oxide film is more stable than the amorphous one, and the corrosion resistance increases with thickness of the oxidic film [11]. Therefore, increasing the anodic potential is beneficial to enhance the corrosion resistance of titanium and its alloy. However, several studies have also shown that the higher anodic potential can result in the increase of the roughness and the formation of micropores on the surface of Ti and its alloy $[12,13]$. As is known to all, a material with a flat and dense surface may have a better corrosion resistance [14]. Sivaet al. [15] studied the effect of surface roughness of industrial pure titanium on corrosion resistance, and electrochemical tests revealed the lower the surface roughness of industrial pure titanium, the better its corrosion resistance. That is because the aggressive ions can be preferentially adsorbed into the pores and cracks of the anodic oxide films, which may cause localized corrosion.

In order to further enhance the corrosion resistance of the anodic oxide film, it is necessary to reduce its surface roughness and porosity while improving its thickness and crystalline. According to literature [16,17], the properties of the anodic oxide films are considerably influenced by the anodization mode, even if the final anodic potential has a constant value. There are mainly three anodization modes, including potentiostatic mode, galvanostatic mode, and potentiodynamic mode. The anodic oxide film formed on potentiostatic mode is thicker and more crystalline than the potentiodynamic mode and galvanostatic mode films $[18,19]$. However, Xing et al. [17] also reported that the potentiodynamic grown film is smoother than the film formed at the potentiostatically mode.

From these previous results, it can be concluded that potentiostatically mode or potentiodynamic mode has its own advantage. Therefore, the purpose of this study to improve the thickness and the crystallinity, while reducing the roughness and improving the surface compactness of the oxide film by an anodization mode named potentiodynamic-aging mode. To our best knowledge, no systematic study has been done to evaluate potentiodynamic-aging mode on the properties of commercial pure titanium (CP-Ti). The goal is to understand the effect of potential on surface characteristic and corrosion resistance of anodic oxide film formed on $\mathrm{CP}$-Ti at the potentiodynamic-aging mode. The surface topography, crystalline, thickness, and composition of $\mathrm{CP}$-Ti oxide films at the potentiodynamic-aging mode as a function of anodic potential in $0.5 \mathrm{M} \mathrm{H}_{2} \mathrm{SO}_{4}$ solution are studied. The electrochemical tests were conducted in $3.5 \mathrm{wt} . \% \mathrm{NaCl}$ solution by means of electrochemical impedance spectroscopy (EIS) and potentiodynamic polarization curves. Electrochemical data were correlated to anodic oxide film composition. In addition, the film growing and crystallization process of anodic oxide films on CP-Ti under potentiodynamic-aging mode are discussed.

\section{Experimental}

\subsection{Specimen Preparation}

The nominal composition of industrial pure Ti used in this research was (wt.\%) C 0.02, N 0.02, Fe 0.10, O 0.15, H 0.0011, and the rest is Ti. The test-pieces were cut into sizes of $50 \times 10 \times 1 \mathrm{~mm}^{3}$, cleaned with acetone, alcohol and deionized water under the ultrasonic condition. Subsequently, the titanium sheets were etched using Kroll's reagent ( $1 \mathrm{~mL} \mathrm{HF}$ and $5 \mathrm{~mL} \mathrm{HNO}_{3}$ in $44 \mathrm{~mL} \mathrm{H}_{2} \mathrm{O}$ ) for $10 \mathrm{~min}$ [20], and then rinsed with deionized water for $20 \mathrm{~min}$ under the ultrasonic condition again. Anodic oxide films were formed in a two-electrode electrochemical cell. Using the test-piece as the anode, a graphite plate as the cathode. The anode and cathode were positioned face-to-face with a $10 \mathrm{~mm}$ distance in $0.5 \mathrm{M} \mathrm{H}_{2} \mathrm{SO}_{4}$. During anodic treatment, the potential was firstly swept from 0 to 10,30 or $50 \mathrm{~V}$ at a constant sweep rate of $1 \mathrm{~V} / \mathrm{s}$, and then was kept at the final potential for 3600 
s. All experiments were carried out at room temperature. The final samples were termed $\mathrm{Ti}_{\mathrm{x}}$, where $\mathrm{x}=10,30$ or 50 .

\subsection{Surface Characterization}

The micromorphology of the sample was observed using scanning electron microscopy (SEM, LEO 1530Vp, Carl Zeiss AG, Heidenheim, Germany) and the acceleration voltage was $15 \mathrm{kV}$. The 3D morphology of passive film was characterized by atomic force microscope (AFM, CSPM-400, China Benyuan nano co., Ltd., Beijing, China). The Si probe tips (force constant: $3.0 \mathrm{~N} / \mathrm{m}$ ) used for the AFM measurements were integral with the V-shaped cantilevers. A Raman spectrometer equipped with an optical microscopy (LabRAM HR Evolution, Horiba Group, Kyoto, Japan) was used to detect the crystallization of anodic oxide films on titanium. The excitation wavelength was $532 \mathrm{~nm}$, and the incident power was $10.4 \mathrm{~mW}$. To eliminate influence on the values of binding energies as a result of the X-ray photoelectron spectroscopy (XPS, PHI5000 Versaprobe-II, Shimadzu co., Ltd., Kyoto, Japan) analysis may charge the sample, all data were corrected by a linear shift so as to the peak maximum of the $\mathrm{C} 1 \mathrm{~s}$ originated from adventitious carbon corresponded to $284.8 \mathrm{eV}$ [21]. An XPS analysis software named Multipak (Shimadzu co., Ltd., Kyoto, Japan) was used to fit the existing forms of Ti and O in passive films. The quantitative elemental analysis was performed determining peak areas and taking into account empirical sensitivity factors for each element. To analyze the thickness and the elemental contents longitudinal changes of the passive film, a $3000 \mathrm{eV} \mathrm{Ar}^{+}$ion beam sputtered on the surface over an area of $4 \times 4 \mathrm{~mm}^{2}$.

\subsection{Corrosion Behavior}

The corrosion resistance of samples was assessed through electrochemical tests conducted on electrochemical workstation in $3.5 \mathrm{wt} . \% \mathrm{NaCl}$ solution. In the three-electrode system, the sample was the working electrode, the platinum coil was the counter electrode and the saturated calomel electrode (SCE) was the reference electrode. Potentiodynamic polarization curves were started from a cathodic potential of -2000 to $3000 \mathrm{mV}_{\mathrm{SCE}}$ at $0.03 \mathrm{mV} / \mathrm{s}$. Electrode impedance spectroscopy (EIS, CHI 760E, Shanghai Chenghua Instrument Co., Ltd., Shanghai, China) tests were proceeded under open-circuit voltage. The alternating current voltage signal varied from $0.01 \mathrm{~Hz}$ to $100 \mathrm{kHz}$ using a $10 \mathrm{mV}$ amplitude to analyze the electrode response. Zsimpwin software was used to fit the EIS experiment data.

\section{Results and Discussion}

\subsection{Surface Properties}

Figure 1 shows photos and the SEM images of $\mathrm{CP}-\mathrm{Ti}, \mathrm{Ti}_{10}, \mathrm{Ti}_{30}$, and $\mathrm{Ti}_{50}$ samples. As shown in Figure $1 \mathrm{a}$, the color of the oxide film formed on bare material is relatively dark grey. From Figure $1 \mathrm{~b}, \mathrm{c}$, it can be seen that the film of bare material has lots of holes and scratches. As shown in Figure 1d,g,j, the sample surface changed into different colors after treated by anodic oxide treatment. It is well-known that titanium and its alloy exhibit various colors because of thin film interference of oxide films [22]. As the anodic voltages increase, the colors of the oxide film change from yellowish orange to grey, which shows that the higher the anodic voltage, the thicker the oxide film produced.

From Figure $1 b, c$, it can be observed that many cracks and nanopores appear on the $\mathrm{Ti}_{10}$ surface. As shown in Figure 1e,f, the passive film formed on $\mathrm{Ti}_{30}$ is relatively dense, some of the nanopores are slightly smaller. Some "flower-like" structures emerge. This is in accordance with the results of the other research [23]. According to the literature [17,24], these "flower-like" structures are mainly composed of crystalline grains, and are mostly attributed to manifestation of the dielectric breakdown of the film. When the anodic potential continued to increase, as shown in Figure 1h,i, the "flower-like" structures grow intensively and spread, covering the film surface and the passive film becomes flat and dense. 

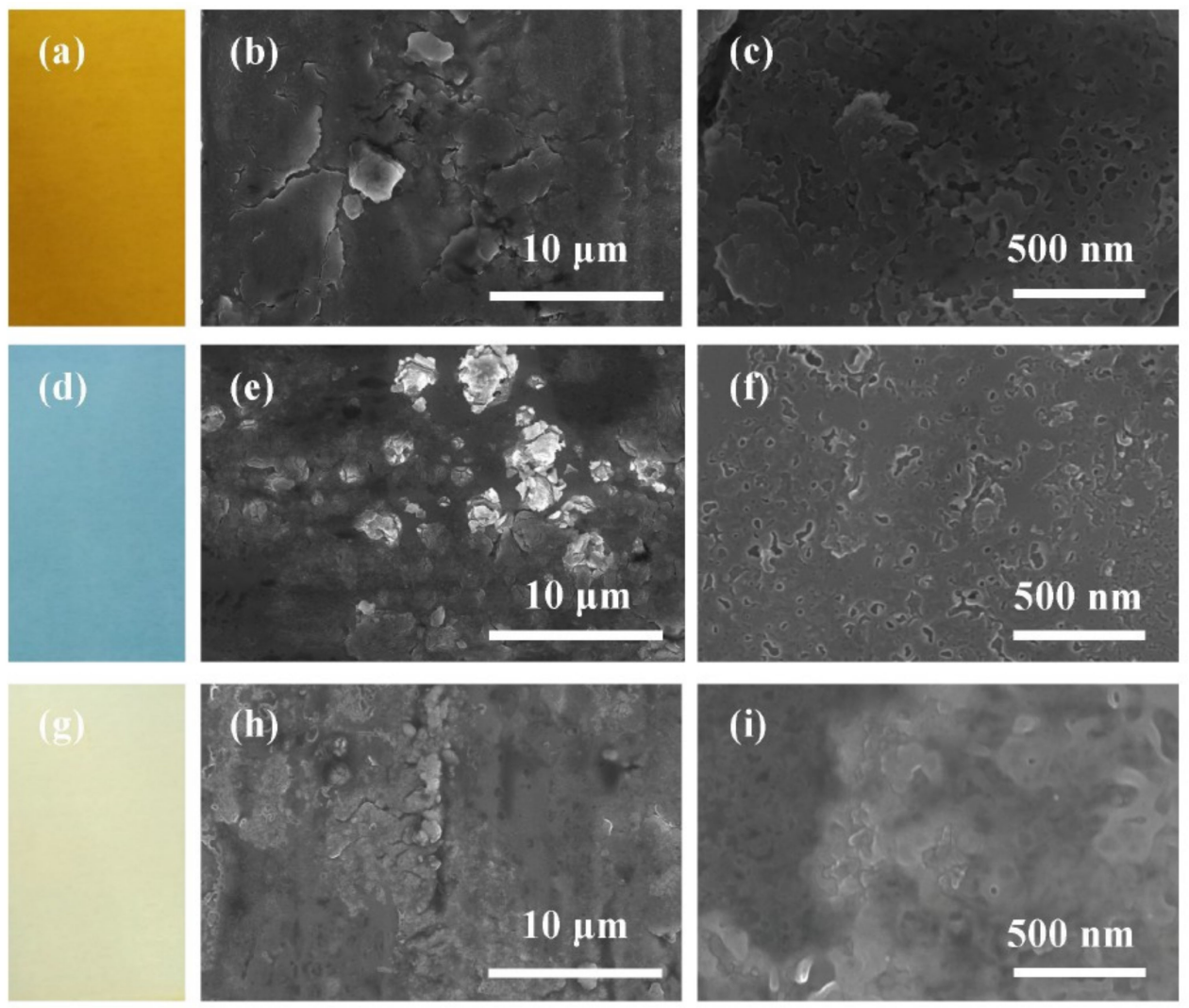

Figure 1. Surface colors and scanning electron microscopy (SEM) images of the surface of the oxide films formed at different voltages: $(\mathbf{a}-\mathbf{c}) \mathrm{Ti}_{10} ;(\mathbf{d}-\mathbf{f}) \mathrm{Ti}_{30} ;(\mathbf{g}-\mathbf{i}) \mathrm{Ti}_{50}$.

Figure 2 presents the AFM images of passive films produced under different anodic potential. Since the surface roughness parameter has an effect on the adhesion, adsorption and differentiation of $\mathrm{Cl}^{-}$[25], it is also an important parameter affecting corrosion resistance [25]. The roughness parameter is generally labeled with $R_{a}$, which represents the arithmetic mean of the deviation of the rough contour from the average line profile measured over the entire length [26]. The roughness measured by AFM of bare material is $121.627 \mathrm{~nm}$, as shown in Figure $2 \mathrm{a}$. $\mathrm{R}_{\mathrm{a}}$ of the $\mathrm{Ti}_{10}$ is calculated to be about 106.566 $n m$ corresponding to $3 \mathrm{D}$ profile as shown in Figure $2 \mathrm{~b}$. The $\mathrm{Ti}_{30}$ revealed a surface roughness $\mathrm{R}_{\mathrm{a}}$ equal to $84.098 \mathrm{~nm}$ (Figure 2c), while $\mathrm{Ti}_{50}$ is quite smooth with a lower surface roughness $\mathrm{R}_{\mathrm{a}}=43.094 \mathrm{~nm}$ (Figure 2d).

Furthermore, no nanocrystalline grains can be found on the surface of CP-Ti (Figure 2e). As shown in Figure 2f, lots of nanocrystalline grains with similar shape and dimension (around $50 \mathrm{~nm}$ ) can be observed on the surface of $\mathrm{Ti}_{10}$. In the case of $30 \mathrm{~V}$, the randomly distributed nanoscale grains grow larger (Figure $2 \mathrm{~g}$ ). For $\mathrm{Ti}_{50}$, the $\mathrm{TiO}_{2}$ nanocrystalline grains join together and form a smooth region (Figure 2h). In summary, when the commercially pure titanium was treated at a higher potential at the potentiodynamic-aging mode, the growth of the oxide film is favored, decreasing its roughness, and increasing its flatness.

The crystallization of the obtained passive films was evaluated by Raman spectrum. Figure 3 shows the optical microscopy photos and Raman spectrum of passive film formed on $\mathrm{Ti}_{10}, \mathrm{Ti}_{30}$, and $\mathrm{Ti}_{50}$. The optical microscopy photos under different anodic potentials are shown in Figure 3a-c. The images of all samples have two distinguishable regions, the dark, and the light region, which means that the crystallization of the passive film is non-uniform. This phenomenon is in accordance with the results of Raman spectrum. 
(a)
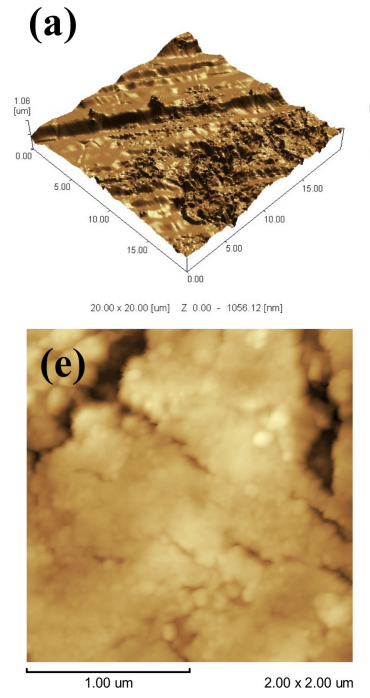

(b)
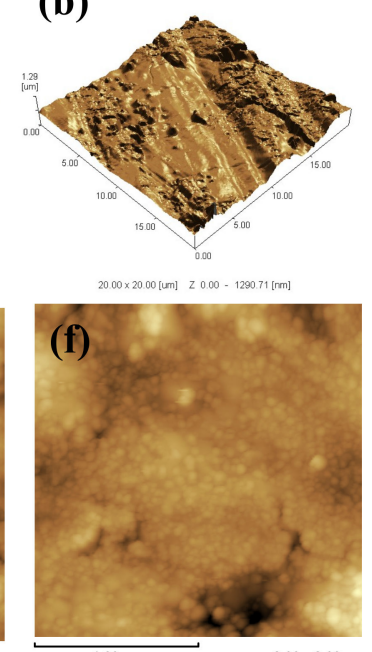

(c)

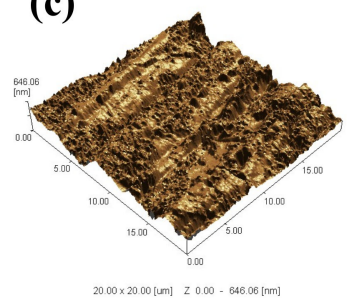

(g)

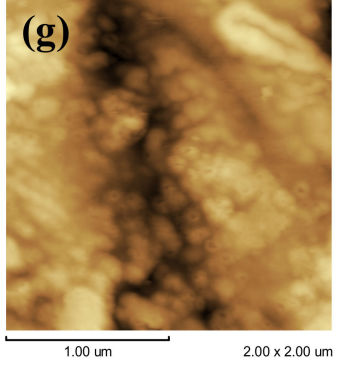

(d)

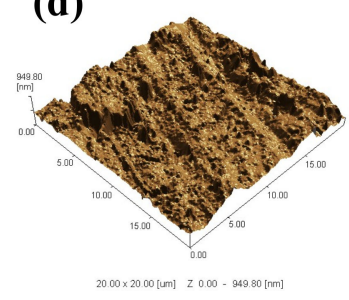

(h)

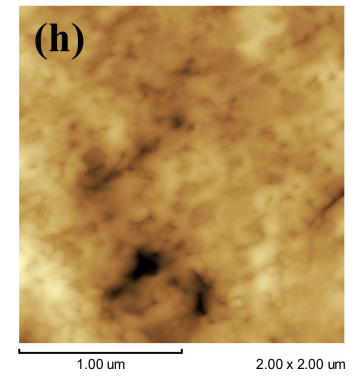

Figure 2. Atomic force microscope (AFM) image of three-dimensional anodic oxide film. (a,e) CP-Ti; $(\mathbf{b}, \mathbf{f}) \mathrm{Ti}_{10} ;(\mathbf{c}, \mathbf{g}) \mathrm{Ti}_{30} ;(\mathbf{d}, \mathbf{h}) \mathrm{Ti}_{50}$.

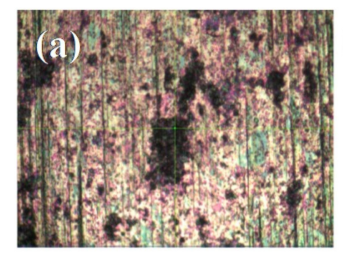

(d)
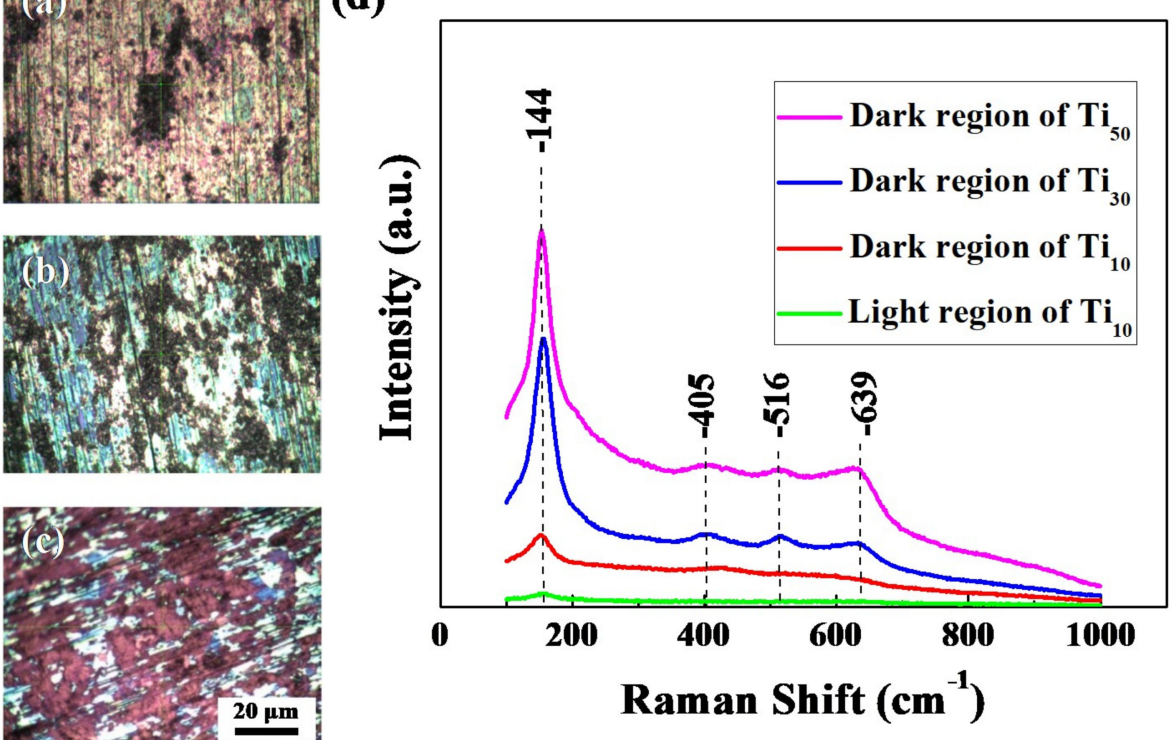

Figure 3. Optical microscopy pictures of passive film formed on different potentials (a) $\mathrm{Ti}_{10},(\mathbf{b}) \mathrm{Ti}_{30}$, (c) $\mathrm{Ti}_{50}$, (d) Raman spectrum of passive film formed on different potentials.

The Raman bands at around 144, 405, 516 and $639 \mathrm{~cm}^{-1}$ are in accordance with the values of the $E_{g}, B_{1 g}, A_{1 g}$ or $B_{1 g}$ and $E_{g}$ modes of anatase phase, respectively. Furthermore, the Raman band at about $144 \mathrm{~cm}^{-1}$ is the long range order of anatase phase, Raman bands at about 405, 516 and $639 \mathrm{~cm}^{-1}$ are the short range ones [27]. When the Raman microlaser beam is centered respectively on the dark and the light region of anodic oxide film grown on the $\mathrm{Ti}_{10}$, the results are shown in the spectrum red and green in Figure 3d. It is clear that a low-frequency $E_{g}$ mode is observed in the dark region, while no Raman band can be found in the light region. The Raman band is weak and has an obvious shift towards lower wave number, which indicates that the passive film formed on $\mathrm{Ti}_{10}$ in dark region is composed of nanometer-scale anatase phase [28]. This phenomenon clearly implies that the dark region is more crystalline than the light region. On the $\mathrm{Ti}_{30}$ samples, the dark regions Raman spectra were composed of a strong band about $144 \mathrm{~cm}^{-1}$ and three weak bands about 405, 516, $639 \mathrm{~cm}^{-1}$, which are attributed to long range order and short range order of anatase phase. Additionally, when 
the anode voltage increased to $50 \mathrm{~V}$, the Raman peaks become sharper and stronger. According to Xing et al. [23], the Raman band intensity is proportional to the film crystallinity. These results clearly show that the crystallization of passive films is enhanced by increasing the anodic potential at the potentiodynamic-aging mode.

The surface chemical state of the anodic oxide films formed at different anodic potentials was characterized via XPS analysis. As Figure 4 shows, the resulting wide-range XPS spectrum of each specimen indicates that $\mathrm{Ti}, \mathrm{O}$ and $\mathrm{C}$ elements in the passive film. The $\mathrm{C} 1 \mathrm{~s}$ peak, which occurs at $284.06 \mathrm{eV}$, is attributed to the surface-contaminant hydrocarbon layer that covers the topmost surface of the samples [29].

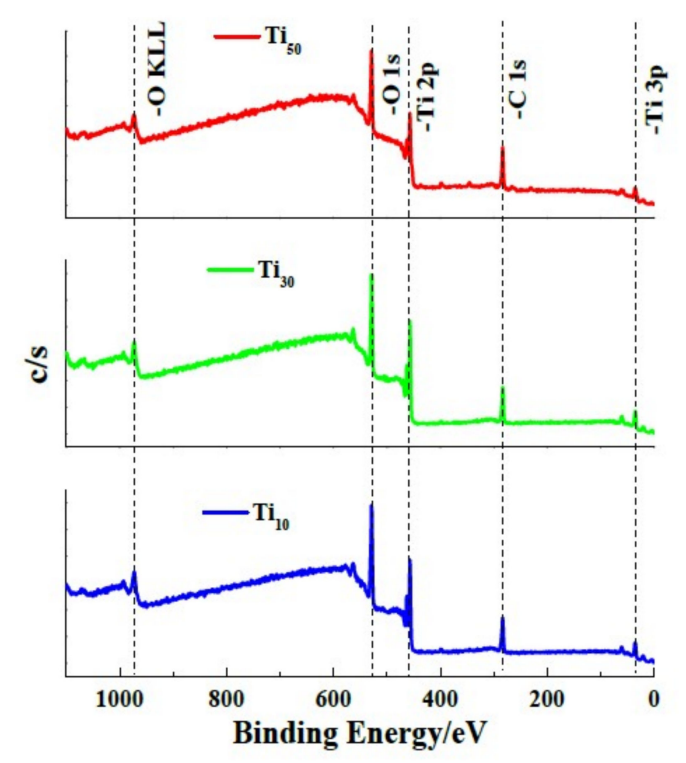

Figure 4. XPS survey spectra of the anodic oxide films formed on different potentials.

XPS measurements were used to characterize the chemical state of passive film formed on specimens and the results are illustrated in Figure 4. By using the results from Wang et al. [30] and Jiang et al. [31], we determined the possible species in anodic oxide films, as shown in Table 1.

Table 1. Energies of XPS-peaks of standards.

\begin{tabular}{|c|c|c|c|c|c|c|}
\hline \multicolumn{4}{|c|}{$\mathrm{Ti} 2 \mathrm{p}_{3 / 2}(\mathrm{eV})$} & \multicolumn{3}{|c|}{ O 1s (eV) } \\
\hline $\mathrm{Ti}$ & $\mathrm{Ti}^{2+}$ & $\mathrm{Ti}^{3+}$ & $\mathrm{Ti}^{4+}$ & $\mathrm{O}^{2-}$ & $\mathrm{OH}^{-}$ & $\mathrm{H}_{2} \mathrm{O}$ \\
\hline 453.6 & 455.9 & 457.3 & 458.7 & 530.2 & 532.5 & 533.4 \\
\hline
\end{tabular}

After deconvolution using Gaussian-Lorentzian functions, Ti 2 $\mathrm{p}_{3 / 2}$ narrow-scan spectrums of the specimens, reveal a major peak at $458.01 \mathrm{eV}$ corresponding to $\mathrm{Ti}^{4+}$ species, as shown in Figure $5 \mathrm{a}$. The $\mathrm{O} 1 \mathrm{~s}$ narrow-scan spectrums, as shown in Figure $5 \mathrm{~b}$, are composed of three peaks, which correspond to $\mathrm{O}^{2-}, \mathrm{OH}^{-}$, and adsorbed water. The $\mathrm{O}^{2-}$ is reported to assign to oxygen atoms in $\mathrm{TiO}_{2}$, and the $\mathrm{OH}^{-}$and the adsorbed water may be from the hydrated titanium oxides. This phenomenon has been reported in other research [23,32]. The Ti $2 \mathrm{p}$ narrow-scan spectrum of all samples indicate that anodic oxidation treatment favors the transformation from lower valence states to $\mathrm{Ti}^{4+}$, and enhancing thermodynamically stability of the anodic oxide film. In addition these peaks reveal the outmost surface $(0 \mathrm{~nm})$ of all samples consist of $\mathrm{TiO}_{2}, \mathrm{Ti}(\mathrm{OH})_{4}$ and $\mathrm{TiO}_{2} \cdot \mathrm{nH}_{2} \mathrm{O}$. 
(a)

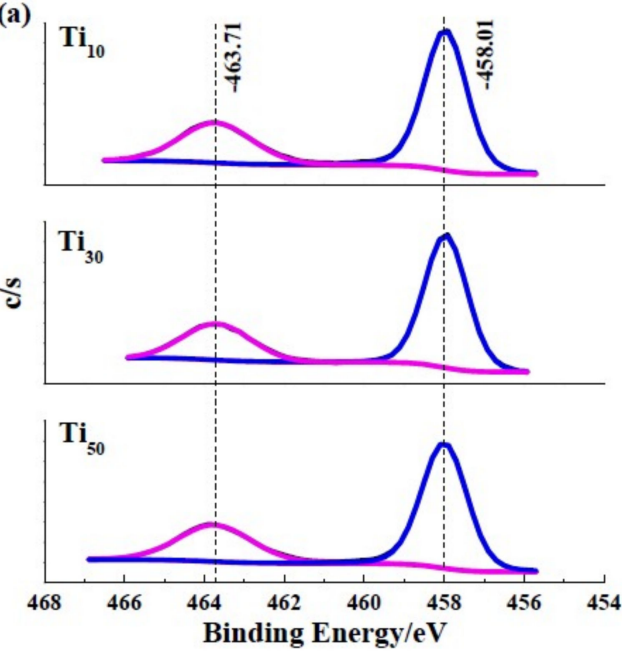

(b)

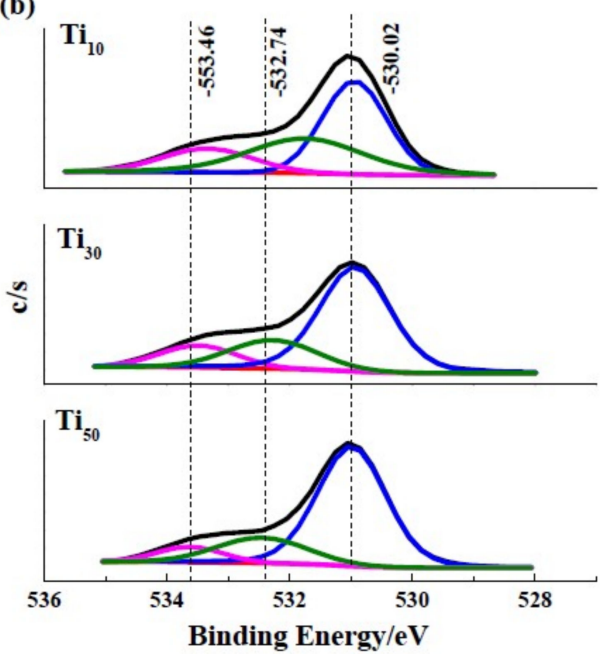

Figure 5. XPS analysis of the samples: (a) the narrow-scan spectrum of Ti $2 p$, (b) the narrow-scan spectrum of $\mathrm{O} 1 \mathrm{~s}$.

The anodic potential effect on the percentage contents of $\mathrm{O}^{2-}, \mathrm{OH}^{-}$and adsorbed water of the anodic oxide film are summarized in Table 2. Compared the contribution of $\mathrm{O} 1 \mathrm{~s}$ components in $\mathrm{Ti}_{10}$, $\mathrm{Ti}_{30}$, and $\mathrm{Ti}_{50}$ samples, it indicates that the $\mathrm{O}^{2-}$ increases and the $\mathrm{OH}^{-}, \mathrm{H}_{2} \mathrm{O}$ decrease with increasing anodic potential. As mentioned by other research [17], the hydroxide group and adsorbed water were unfavorable for the crystallization. This result indicates that enhancing the anodic voltage has a positive effect on the formation of dehydrated and $\mathrm{TiO}_{2}$ dominated anodic oxide film, which is in accordance with the results of Roman spectrum.

Table 2. The contribution of $\mathrm{O} 1$ s components on the surface of $\mathrm{Ti}_{10}, \mathrm{Ti}_{30}$ and $\mathrm{Ti}_{50}$.

\begin{tabular}{cccc}
\hline \multirow{2}{*}{ Samples } & \multicolumn{3}{c}{ The Contribution of $\mathbf{O}$ 1s Components $\mathbf{( \% )}$} \\
\cline { 2 - 4 } & $\mathbf{O}^{\mathbf{2}-}$ & $\mathbf{O H}^{-}$ & $\mathbf{H}_{\mathbf{2}} \mathbf{O}$ \\
\hline $\mathrm{Ti}_{10}$ & 73.65 & 21.88 & 4.47 \\
$\mathrm{Ti}_{30}$ & 78.03 & 17.59 & 4.38 \\
$\mathrm{Ti}_{50}$ & 84.09 & 12.99 & 2.92 \\
\hline
\end{tabular}

In order to compare the thickness of the passive film formed on different anodic potentials, XPS depth profiles were carried out. Figure 6 depicts Ti and $\mathrm{O}$ atomic percentages varying with sputtering depth of each sample. The thickness of the anodic oxide films can be calculated by the XPS depth profiles at the point where the oxygen-atoms concentration dropped to $50 \%$ of its maximum value $[33,34]$, in which case the value is calculated to be about $35 \%$. Figure 6 a shows that the thickness of anodic oxide film formed on $10 \mathrm{~V}$ is about $80 \mathrm{~nm}$. Figure $6 \mathrm{~b}$ reveals that the thickness of the anodic oxide film formed on $30 \mathrm{~V}$ is about $114 \mathrm{~nm}$. Whereas, the thickness of the anodic oxide film formed on $50 \mathrm{~V}$ is about $160 \mathrm{~nm}$ (Figure 6c). The grown rate abstracted from Figure 6 was about $1.5 \mathrm{~nm} \mathrm{~V}^{-1}$, which is commonly found on other passivated metals [35].

The XPS narrow-scan spectrum spectra recorded from surface to depth of the anodic oxide films exhibited the chemical state of Ti 2p and O 1s peaks, as shown in Figure 7a,c,f and Figure 7b,d,e respectively. For $\mathrm{Ti}_{10}$ sample (as shown in Figure 7a,b), the Ti2p spectra in a depth of $34 \mathrm{~nm}$ show the presence of $\mathrm{Ti}^{2+}$. Furthermore, $\mathrm{O}$ element existed in the form of $\mathrm{O}^{2-}, \mathrm{OH}^{-}$. These results reveal the anodic oxide film is consisted of $\mathrm{TiO}_{2}, \mathrm{Ti}(\mathrm{OH})_{4}$, and $\mathrm{TiO}$ in the depth from 0 to $34 \mathrm{~nm}$. In the sputtering depth from 34 to $72 \mathrm{~nm}, \mathrm{Ti}^{3+}$ and metallic $\mathrm{Ti}^{0}$ occurred, and the peak intensity from $\mathrm{Ti}^{2+}$ weakened. The XPS data suggest that the anodic oxide film in this region mainly consists of $\mathrm{Ti}_{2} \mathrm{O}_{3}$, $\mathrm{TiO}$, and metallic $\mathrm{Ti}^{0}$. In a depth of $120 \mathrm{~nm}$, the peaks attributed to $\mathrm{Ti}^{3+}$ and $\mathrm{Ti}^{2+}$ disappeared and the peak attributed to 
metallic $\mathrm{Ti}^{0}$ became higher. For $\mathrm{Ti}_{30}$ sample (as shown in Figure $7 \mathrm{c}, \mathrm{d}$ ), the Ti $2 \mathrm{p}$ spectra recorded at 52 $\mathrm{nm}$ is assigned to $\mathrm{Ti}^{4+}$ and $\mathrm{Ti}^{2+}$. The $\mathrm{O} 1$ s spectra recorded in the depth of $52 \mathrm{~nm}$ is composed of $\mathrm{O}^{2-}$ and $\mathrm{OH}^{-}$. The XPS data indicate that chemical compositions of the anodic oxide film are $\mathrm{TiO}_{2}, \mathrm{TiO}$, and $\mathrm{Ti}(\mathrm{OH})_{4}$ in the depth of $0-52 \mathrm{~nm}$. In the depth of $75 \mathrm{~nm}$, the peaks attributed to $\mathrm{Ti}^{4+}$ weakened and the peaks due to $\mathrm{Ti}^{2+}$ became higher. In the depth from 75 to $143 \mathrm{~nm}$, the anodic oxide film is composed of $\mathrm{Ti}_{2} \mathrm{O}_{3}, \mathrm{TiO}$, and metallic $\mathrm{Ti}$. In the depth of $196 \mathrm{~nm}$, both $\mathrm{Ti}_{2} \mathrm{O}_{3}$ and $\mathrm{TiO}$ disappeared and only the metallic $\mathrm{Ti}^{0}$ is observed. For $\mathrm{Ti}_{50}$ sample (as shown in Figure $7 \mathrm{e}, \mathrm{f}$ ), the Ti $2 \mathrm{p}$ spectra recorded at $75 \mathrm{~nm}$ is composed of $\mathrm{Ti}^{4+}$ and $\mathrm{Ti}^{3+}$. The $\mathrm{O}$ element in this depth is $\mathrm{O}^{2-}$ and $\mathrm{OH}^{-}$. The XPS results reveal that the components in the anodic oxide film are $\mathrm{TiO}_{2}, \mathrm{Ti}_{2} \mathrm{O}_{3}$, and $\mathrm{Ti}(\mathrm{OH})_{4}$ in the depth from 0 to $75 \mathrm{~nm}$. In the depth from 75 to $124 \mathrm{~nm}$, the anodic oxide film is composed of $\mathrm{TiO}_{2}$, $\mathrm{TiO}$, and $\mathrm{Ti}(\mathrm{OH})_{4}$. In the depth of 124-175 nm, the anodic oxide film is composed of $\mathrm{TiO}_{2}, \mathrm{Ti}_{2} \mathrm{O}_{3}, \mathrm{Ti}(\mathrm{OH})_{4}$ and metallic $\mathrm{Ti}^{0}$. In the depth of 175-196 nm, the major constituents of the film are $\mathrm{TiO}$ and metallic $\mathrm{Ti}^{0}$. In the depth of $232 \mathrm{~nm}$, only the metallic $\mathrm{Ti}^{0}$ can be detected. In addition, metallic $\mathrm{Ti}^{0}$ can be found throughout the anodic oxide film and mainly exist near the substrate in each sample.

The XPS results also show that the anodic oxide film are mainly composed of $\mathrm{TiO}_{2}, \mathrm{Ti}_{2} \mathrm{O}_{3}, \mathrm{TiO}$, metallic $\mathrm{Ti}^{0}$, $\mathrm{Ti}(\mathrm{OH})_{4}$, and $\mathrm{TiO}_{2} \cdot \mathrm{H}_{2} \mathrm{O}$. Therefore, the XPS analysis provides many extra pieces of evidence to support the discussions of SEM and Raman spectrum to clarify the relationship between compositions of anodic oxide films and anodic potentials.
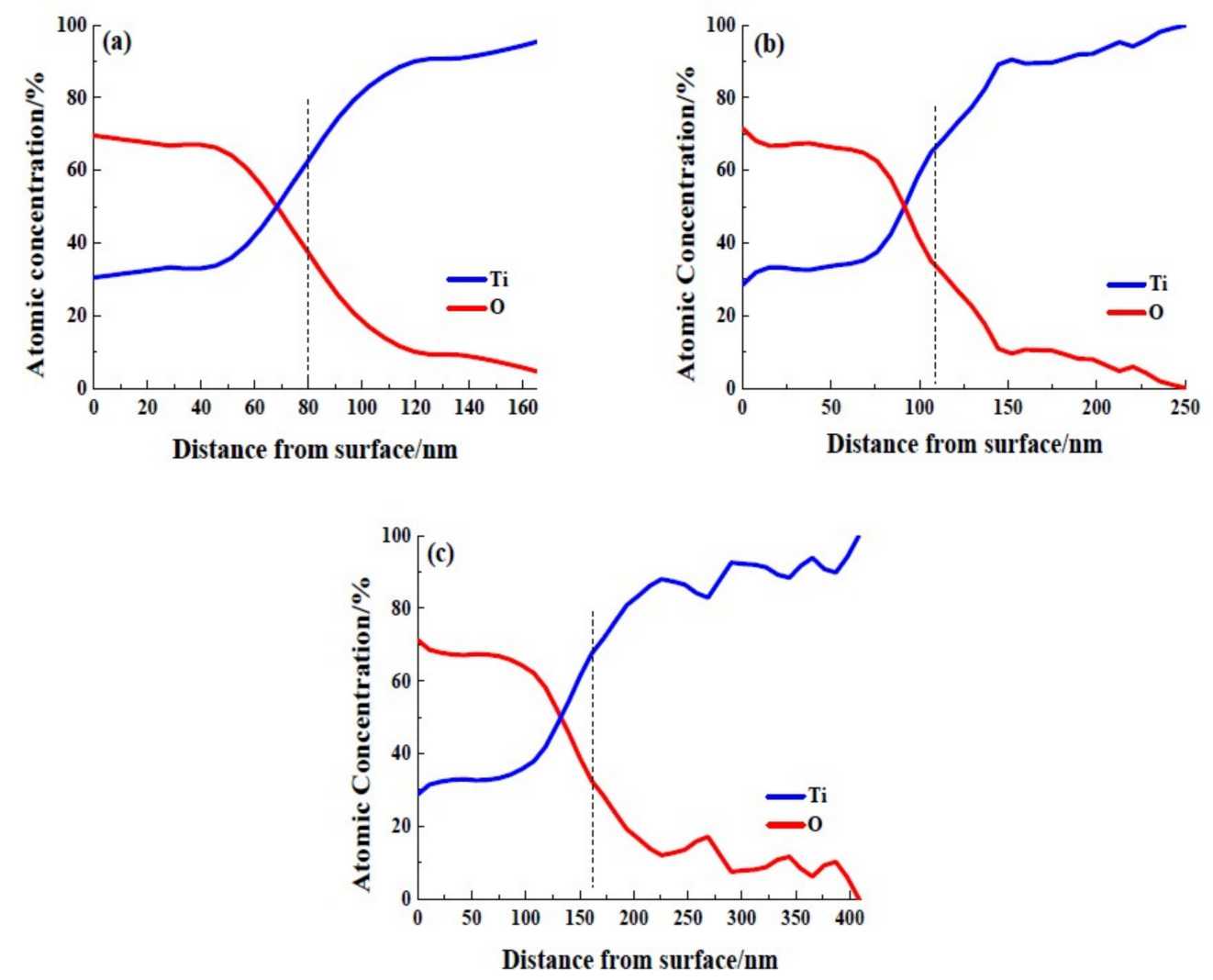

Figure 6. XPS depth profile of passive film and oxide film thickness vs. the anodic potential (a) $\mathrm{Ti}_{10}$; (b) $\mathrm{Ti}_{30} ;$ (c) $\mathrm{Ti}_{50}$. 

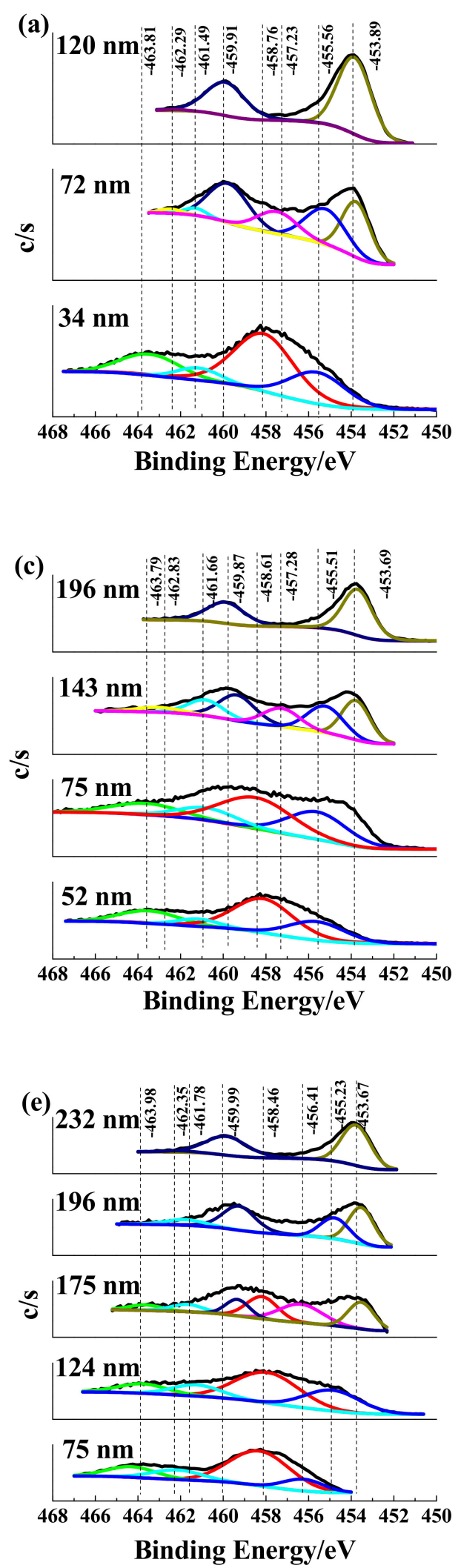
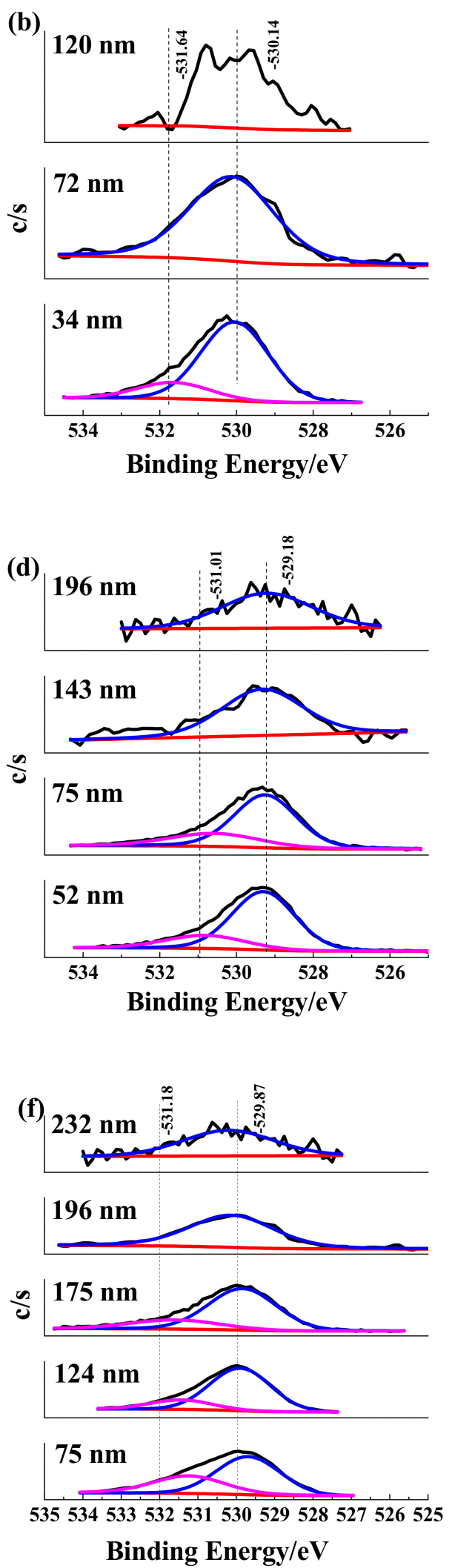

Figure 7. High-resolution XPS spectra of $\mathrm{Ti} 2 \mathrm{p}$ and $\mathrm{O} 1$ s obtained from $\mathrm{Ti}_{10}, \mathrm{Ti}_{30}$, and $\mathrm{Ti}_{50} \cdot(\mathbf{a}, \mathbf{b}) \mathrm{Ti}_{10}$; $(\mathbf{c}, \mathbf{d}) \mathrm{Ti}_{30} ;(\mathbf{e}, \mathbf{f}) \mathrm{Ti}_{50}$. 


\subsection{Electrochemical Tests}

Figure 8 shows potentiodynamic polarization curves measured in $3.5 \mathrm{wt} . \% \mathrm{NaCl}$ solution. In the present case, the cathodic reduction reaction is oxygen absorption reaction [36]. The chemical equation may be:

$$
\mathrm{O}_{2}+2 \mathrm{H}_{2} \mathrm{O}+4 \mathrm{e}^{-} \rightarrow 4 \mathrm{OH}^{-}
$$
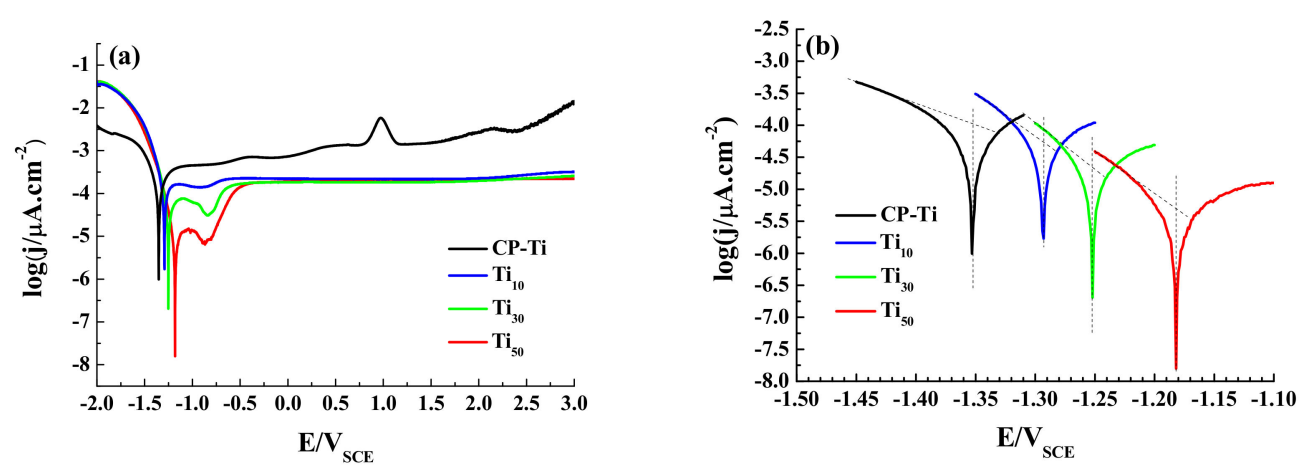

Figure 8. Potentiodynamic polarization curves of the $\mathrm{CP}-\mathrm{Ti}, \mathrm{Ti}_{10}, \mathrm{Ti}_{30}$ and $\mathrm{Ti}_{50}$ samples in $3.5 \mathrm{wt} . \%$ $\mathrm{NaCl}$ solution. (a) Potentiodynamic polarization curves for all samples; (b) Tafel extrapolation plot for all samples.

The corrosion potential $\left(\mathrm{E}_{\mathrm{corr}}\right)$ and corrosion current density $\left(\mathrm{j}_{\mathrm{corr}}\right)$ were obtained from the Figure 8 by Tafel extrapolation and summarized in Table 3 [37]. In order to obtain the accurate extrapolation results, anodic or cathodic branch should exhibit Tafel behavior. In addition, the extrapolation should be used at least 50 to $100 \mathrm{mV}$ away from $\mathrm{E}_{\text {corr }}$ [38]. As Ti and its alloy do not have Tafel behavior in anodic branch [39], only the cathodic Tafel line was used to extrapolate to the $\mathrm{E}_{\text {corr }}$ to determine the $j_{\text {corr }}$ in this study. $E_{\text {corr, }}$ values of $-1.352,-1.297,-1.252$ and $-1.181 \mathrm{~V}_{\mathrm{SCE}}$, and $j_{\text {corr }}$, values of $1.258 \times 10^{-4}, 5.623 \times 10^{-5}, 1.995 \times 10^{-5}$, and $5.623 \times 10^{-6} \mu \mathrm{A} \cdot \mathrm{cm}^{-2}$ were obtained for the CP-Ti, $\mathrm{Ti}_{10}, \mathrm{Ti}_{30}$, and $\mathrm{Ti}_{50}$, respectively. The higher $\mathrm{E}_{\mathrm{corr}}$ and the lower $\mathrm{j}_{\mathrm{corr}}$ means the lower susceptibility to corrosion [40]. The results indicate that the anodic oxidation treatment has a positive effect of improving the corrosion resistance of $\mathrm{CP}$-Ti. Furthermore, as the anodic potential increases, the $\mathrm{E}_{\mathrm{corr}}$ increases and $j_{\text {corr }}$ decreases. This is a clear indication that the anodic potential has a positive effect on the corrosion resistance of CP-Ti.

Table 3. Electrochemical parameters of the $\mathrm{CP}-\mathrm{Ti}, \mathrm{Ti}_{10}, \mathrm{Ti}_{30}$ and $\mathrm{Ti}_{50}$ in $3.5 \mathrm{wt} . \% \mathrm{NaCl}$ solution at room temperature.

\begin{tabular}{ccc}
\hline Sample & $\mathrm{E}_{\text {corr }} / \mathrm{V}_{\text {SCE }}$ & $\mathbf{j}_{\text {corr }}\left(\mu \mathbf{A ~ c m}{ }^{-2)}\right.$ \\
\hline $\mathrm{CP}-\mathrm{Ti}$ & -1.352 & $1.258 \times 10^{-4}$ \\
$\mathrm{Ti}_{10}$ & -1.297 & $5.623 \times 10^{-5}$ \\
$\mathrm{Ti}_{30}$ & -1.252 & $1.995 \times 10^{-5}$ \\
$\mathrm{Ti}_{50}$ & -1.181 & $5.623 \times 10^{-6}$ \\
\hline
\end{tabular}

Electrochemical impedance spectroscopy (EIS) was used to obtain important parameters associated with the anodic oxide film, such as the charge transfer resistance, capacitance and thickness of the anodic oxide film [41]. It can be seen that Nyquist plots were characterized by flattened and incomplete semi-circles in the entire frequency range, as shown in Figure 9a. This semi-circle is associated with the charge transfer reaction occurring at the metal/electrolyte interface. The larger the diameter of the arc is, the greater the electron transfer resistance is, and the stronger the stability of the oxide film is [42]. The semi-circle increases with increasing anodic potential, which means that the anodic potential has greatly improved the corrosion resistance of CP-Ti. The Nyquist plot of the $\mathrm{Ti}_{50}$ is almost a straight line which indicates good insulating properties of the anodic oxide film. 

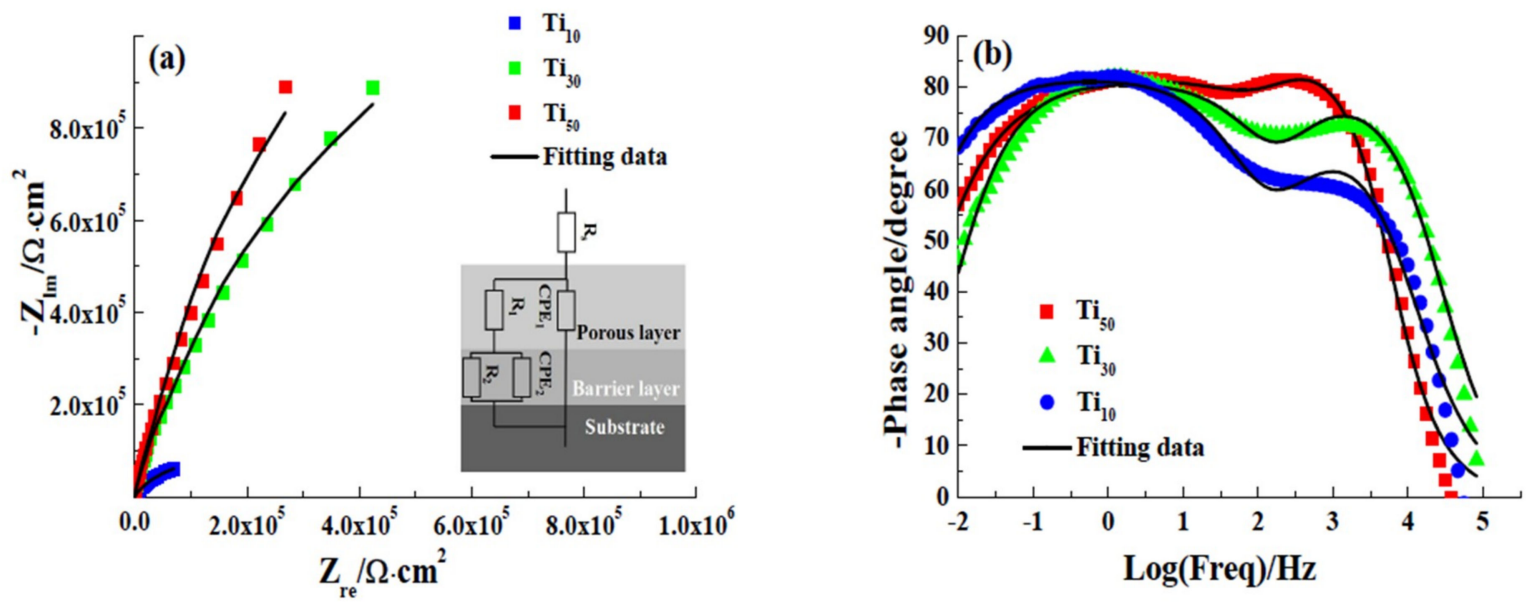

Figure 9. Nyquist and Bold plots of the $\mathrm{Ti}_{30}$ and $\mathrm{Ti}_{50}$ samples in $3.5 \mathrm{wt} \% \mathrm{NaCl}$. (a) Nyquist plots; (b) Bold plots.

Furthermore, two time constants are well distinguished in the Bode plot. According to Robin [43], the anodic oxide film formed on Ti and its alloy is a double layer structure which consists of a porous outer layer and a barrier inner layer. The EIS were fitted using an electrical equivalent circuit (EEC), in which two time constants was chosen to represent the double layer structure. In this EEC, $R_{S}$ is the solution resistance, $R_{1}$ and $R_{2}$ are the charge transfer resistances of the porous layer and barrier layer. The symbol $Q$ corresponding to a constant phase element (CPE) with varying $\alpha$, stands for the possibility of a non-ideal capacitance behavior. The symbol $Q$ corresponding to a constant phase element (CPE) with varying $\alpha$, stands for the possibility of a non-ideal capacitance behavior. $\mathrm{Q}_{1}$ and $\mathrm{Q}_{2}$ are the $\mathrm{CPE}$ of the porous outer layer and barrier inner layer. The mathematical formulation of $\mathrm{CPE}$ can be obtained by Equation (2) [44]:

$$
\mathrm{Z}_{\mathrm{CPE}(\omega)}=\frac{1}{\mathrm{Q}(j w)^{\alpha}}
$$

where $Q$ is the magnitude of the CPE in $F \cdot \mathrm{cm}^{-2} \mathrm{~s}^{\alpha-1}, \omega$ is the angular frequency $(\omega=2 \pi \mathrm{f})$ in $\mathrm{rad} \cdot \mathrm{s}^{-1}$, $\mathrm{f}$ is the frequency in $\mathrm{Hz}, \mathrm{j}$ is the imaginary number $(j=\sqrt{-1}), \alpha$ is the CPE exponent which is adjusted between 0 and 1. For $\alpha=1$, the CPE represents an ideal capacitor; for $\alpha=0$, the CPE represents an ideal resistor; for $\alpha=0.5$, the CPE behaves a Warburg impedance with diffusion character, for $0.5<\alpha<1$, the CPE describes a distribution of dielectric relaxation times in the frequency domain $[25,45]$. The value of $\alpha$ is related to surface state [46].

Table 4 shows the fitted results of the impedance spectra. The Chi-squared $\left(\chi^{2}\right)$ values were lower than $10^{-3}$ which indicates satisfactory agreement between the experimental and fitting data. $R_{\mathrm{s}}$ remains almost constant in all tests. $R_{1}$ increases from $1.79 \Omega \cdot \mathrm{cm}^{-2}$ for the $T_{10}$ to $43.78 \Omega \cdot \mathrm{cm}^{-2}$ for the $\mathrm{Ti}_{30}$ and further to $89.45 \Omega \cdot \mathrm{cm}^{-2}$ for the Ti ${ }_{50}$, respectively. $\mathrm{R}_{1}$ was increased by two orders of magnitude through enhancing the anodic potential. Additionally, $\mathrm{R}_{2}$ of the $\mathrm{Ti}_{10}, \mathrm{Ti}_{30}$ and $\mathrm{Ti}_{50}$ are about $489.53,502.56$, and $512.48 \Omega \cdot \mathrm{cm}^{-2}$, respectively. It is clear that the values of $R_{2}$ are higher than the $R_{1}$ values, indicating that the inner layer is a more compact film than the outer layer. However, $\mathrm{R}_{2}$ increase slowly with the increment of anodic potential, which reflects that the increase of potential has little effect on the inner layer. The value of $\mathrm{R}_{1}$ depends strongly on the existence of pores, channels or cracks which the solution can penetrate [47]. Combined the results of SEM, Raman spectrum, XPS, it is revealed that the surface roughness is decreased, the density and the crystallinity is increased, and the resistance of the outer porous layer significantly improved with increasing the potential. 
Table 4. Fitting data of electrode impedance spectroscopy (EIS) for the $\mathrm{Ti}_{30}$ and $\mathrm{Ti}_{50}$.

\begin{tabular}{|c|c|c|c|c|c|c|c|c|}
\hline Samples & $\begin{array}{c}R_{\mathrm{s}} \\
\left(\mathrm{k} \Omega \cdot \mathrm{cm}^{2}\right)\end{array}$ & $\begin{array}{c}\mathrm{Q}_{1} / 10^{-5} \\
\left(\Omega^{-1} \cdot \mathrm{cm}^{-2} \mathrm{~s}^{\alpha}\right)\end{array}$ & $\alpha_{1}$ & $\begin{array}{c}\mathrm{Q}_{2} / 10^{-5} \\
\left(\Omega^{-1} \cdot \mathrm{cm}^{-2} \mathrm{~s}^{\alpha}\right)\end{array}$ & $\alpha_{2}$ & $\begin{array}{c}\mathrm{R}_{1} \\
\left(\mathrm{k} \Omega \cdot \mathrm{cm}^{2}\right)\end{array}$ & $\begin{array}{c}R_{2} \\
\left(\mathrm{k} \Omega \cdot \mathrm{cm}^{2}\right)\end{array}$ & $\chi^{2}\left(10^{-4}\right)$ \\
\hline $\mathrm{Ti}_{10}$ & 1.02 & 8.5501 & 0.92 & 2.5680 & 0.67 & 1.79 & 489.53 & 3.47 \\
\hline $\mathrm{Ti}_{30}$ & 1.12 & 2.5727 & 0.89 & 1.7535 & 0.64 & 43.78 & 502.56 & 2.87 \\
\hline $\mathrm{Ti}_{50}$ & 1.08 & 1.9826 & 0.93 & 1.3068 & 0.59 & 89.45 & 512.48 & 2.67 \\
\hline
\end{tabular}

Furthermore, the value of $\mathrm{Q}$ decreases with increasing applied potential. The increase of transfer charge resistances and the decreased value of $Q$ indicated continuous growth of the anodic oxide film with the increment of potential value.

The CPE used in EEC has been converted into a pure capacitance (C) via Equation (3) [48]:

$$
\mathrm{C}=\frac{(\mathrm{Q} \cdot \mathrm{R})^{\frac{1}{\alpha}}}{\mathrm{R}}
$$

where $\mathrm{R}$ is the film resistance, $\mathrm{Q}$ is the magnitude of the CPE, $\alpha$ is the CPE exponent. The values of $\mathrm{C}_{1}$ of $\mathrm{Ti}_{10}, \mathrm{Ti}_{30}$, and $\mathrm{Ti}_{50}$ are $0.08121,0.02611$, and $0.02078 \mu \mathrm{F} \mathrm{cm}{ }^{-2}$, respectively. $\mathrm{C}_{2}$ decreases from $0.08935 \Omega \cdot \mathrm{cm}^{-2}$ for the $\mathrm{Ti}_{10}$ to $0.05964 \Omega \cdot \mathrm{cm}^{-2}$ for the $\mathrm{Ti}_{30}$ and further to $0.04896 \Omega \cdot \mathrm{cm}^{-2}$ for the $\mathrm{Ti}_{50}$, respectively. It can be seen that both $C_{1}$ and $C_{2}$ values decrease with the increment of potential value insulating the growth of the anodic oxide film. The thickness of the anodic oxide film can be calculated using Equation (4):

$$
\mathrm{L}=\frac{\varepsilon \varepsilon_{0}}{\mathrm{C}}
$$

where $\varepsilon$ is the relative dielectric constant of the film, $\varepsilon_{0}$ is the dielectric constant in vacuum $(8.8542 \times$ $10^{-14} \mathrm{~F} \cdot \mathrm{cm}^{-1}$ ) and L denotes the film thickness. As the Raman results show that crystalline form of the film is anatase, the $\varepsilon$ of porous outer layer can be considered as 48 [49]. Based on the XPS results, the chemical condition of barrier inner layer is amorphous titanium oxide, hence the value of $\varepsilon$ is taken as 33 [50]. Thickness of the barrier inner layer and porous outer layer of anodic oxide films formed at different potentials are shown in Table 5, it is clear that the porous outer layer thickness is larger than the barrier inner layer. Moreover, the potential has a greater influence on the thickness of the outer porous layer.

Table 5. Capacitance and thickness of porous outer layer and barrier inner layer for titanium anodized films formed under different potentials.

\begin{tabular}{ccccc}
\hline Samples & $\mathbf{C}_{\mathbf{1}}\left(\boldsymbol{\mu F} \cdot \mathbf{c m}^{-\mathbf{2}}\right)$ & $\mathbf{C}_{\mathbf{2}}\left(\boldsymbol{\mu F} \cdot \mathbf{c m}^{-\mathbf{2}}\right)$ & $\mathbf{L}_{\mathbf{1}}(\mathbf{n m})$ & $\mathbf{L}_{\mathbf{2}}(\mathbf{n m})$ \\
\hline $\mathrm{Ti}_{10}$ & 0.08121 & 0.08935 & 52.33 & 32.68 \\
$\mathrm{Ti}_{30}$ & 0.02611 & 0.05964 & 162.75 & 49.86 \\
$\mathrm{Ti}_{50}$ & 0.02078 & 0.04896 & 204.48 & 59.64 \\
\hline
\end{tabular}

The EIS results demonstrate that increasing anodic potential positive affects the protective properties of the anodic oxide films formed on CP-Ti. Increasing the potential can increase the thickness of the anodic oxide film and the charge transfer resistance, and the effect on the outer layer is more obvious.

\subsection{Discussion}

I-t curves of CP-Ti under potentiodynamic-aging mode at 10, 30 and $50 \mathrm{~V}$ are shown in Figure 10. It can be seen from the curves that the current density is very large at the first stage. Subsequently, the current density decreases dramatically during the first few seconds. Finally it remains at steady state until the end of the anodic treatment. It can be indicated that the oxide film has been formed in only a few seconds and the current fluctuations may be related to the oxygen evolution reaction (OER) [51]. Moreover, it can be also found that after the initial drop, the steady state current density is much larger 
for CP-Ti anodization at higher anodic potential. Additionally, the larger current density at higher anodic potential means that the film growth is higher [52].

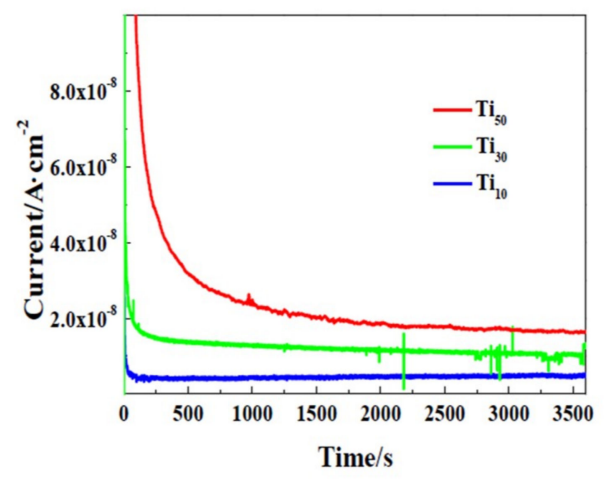

Figure 10. Chrono-amperometric curves of CP-Ti anodization under potentiodynamic-aging mode at 10,30 and $50 \mathrm{~V}$.

Based on the results mentioned above, the growth and crystallization process of passive films under potentiodynamic-aging mode are shown in Figures 11 and 12. According to our previous studies [53], the oxide film of titanium is an n-type semiconductors, which indicates the defects in the oxide film are donors, such as oxygen vacancies and titanium interstitials [54]. The formation energy of oxygen vacancies and titanium interstitials is 2.7 and $4.7 \mathrm{eV}$, respectively [55]. Therefore, oxygen vacancies are considered to be dominant donors. However, titanium interstitials is also under consideration in the present study.

These point defects transport through the oxide film and undergo defect reactions at the Ti/oxide film (Ti/f) and film/solution (f/s) interfaces. According to Veluchamy et al. [56], the transport and reaction of these point defects determine the growth of the oxide film. The point defect model (PDM) was used to describe the growth process of oxide films on Ti surfaces and can be schematically illustrated in Figure 10 and R1-R8 (Figure 11).

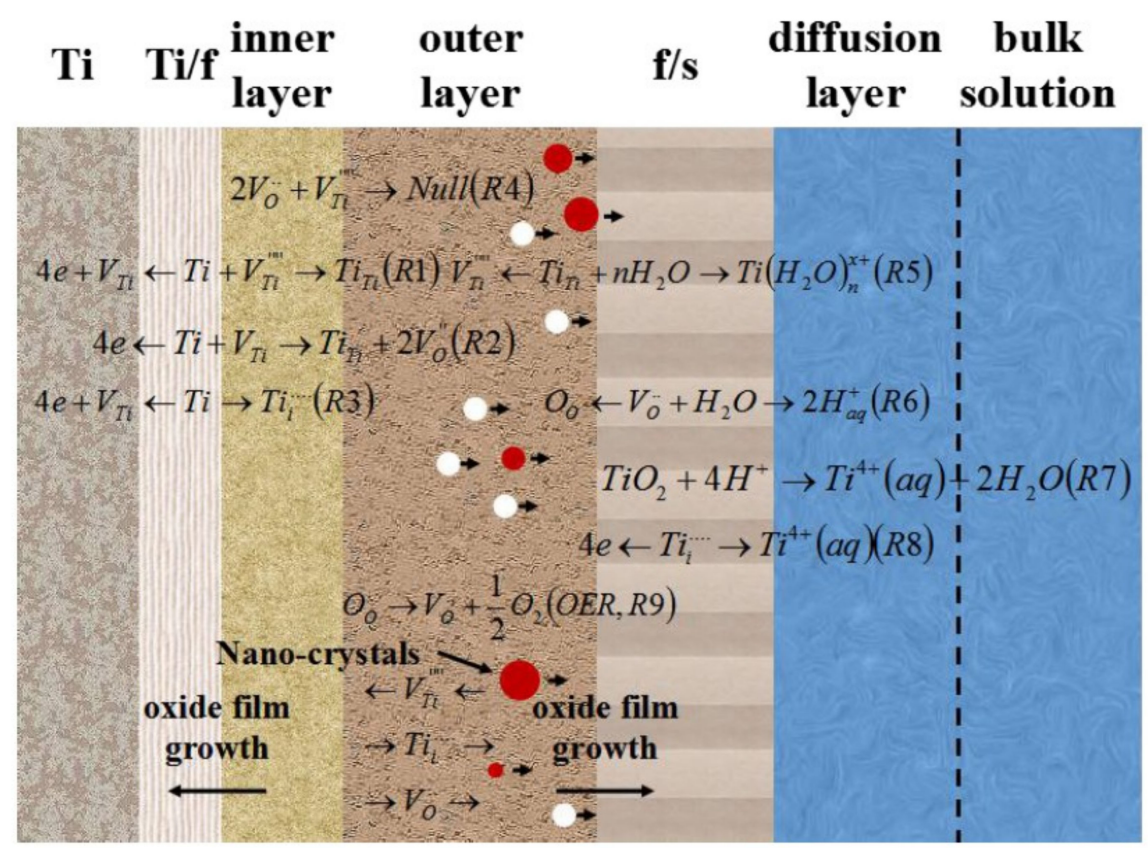

Figure 11. Schematic illustration of the growth process of oxide films. 


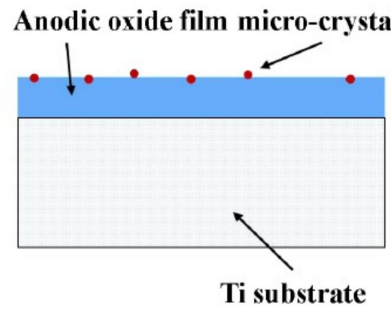

Potentiodynamic stage
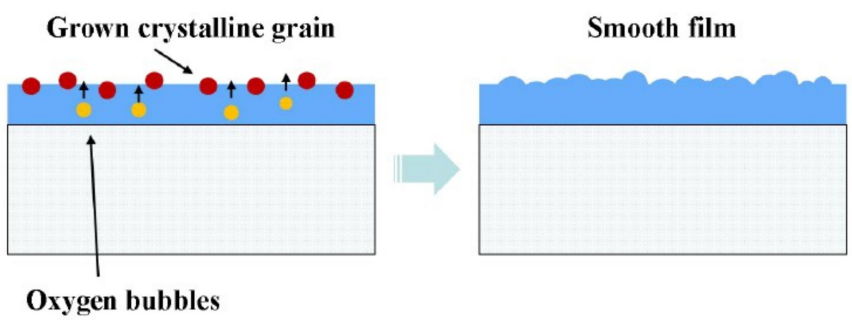

Aging stage

Figure 12. Schematic illustration of the crystallization process of oxide films under different potential.

The equations are expressed in Kröger-Vink notation [57], where the $\mathrm{V}_{\mathrm{Ti}}$ represents Ti vacancy, $\mathrm{V}_{\mathrm{Ti}}{ }^{\prime \prime \prime \prime}$ repesents $\mathrm{Ti}$ cation vacancy, $\mathrm{V}_{\mathrm{O}}{ }^{\bullet}$ represents $\mathrm{O}$ vacancy, $\mathrm{Ti}_{\mathrm{Ti}}$ represents $\mathrm{Ti}$ in $\mathrm{Ti}$ site on the cation sublattice, $\mathrm{Ti}_{\mathrm{i}}{ }^{\cdots \bullet \bullet}$ represents $\mathrm{Ti}$ cation interstitial, $\mathrm{O}_{\mathrm{O}}$ represents oxide ion in oxide site on the anion sublattice, $\mathrm{Ti}^{4+}$ (aq) represents $\mathrm{Ti}^{4+}$ in solution, $\mathrm{Ti}\left(\mathrm{H}_{2} \mathrm{O}\right)_{\mathrm{n}}{ }^{4+}$ repesents $\mathrm{Ti}$ and hydrated titanium complexes, respectively. The electrical field of the oxide film enables the defects through the film at room temperature $[57,58]$.

$\mathrm{R} 1-\mathrm{R} 3$ happen at the $\mathrm{Ti} /$ inner layer interface. $\mathrm{R} 1$ expresses the submergence of cation vacancies, $\mathrm{V}_{\mathrm{Ti}}{ }^{\prime \prime \prime}$ into the Ti lattice. It results in the formation of $\mathrm{Ti}_{\mathrm{Ti}}$ in the oxide lattice and a vacancy $\mathrm{V}_{\mathrm{Ti}}$ into the Ti lattice. $\mathrm{R} 2$ represents Ti reacting with $\mathrm{V}_{\mathrm{Ti}}$ which generates $\mathrm{Ti}_{\mathrm{Ti}}$ and $\mathrm{V}_{\mathrm{O}} \bullet \bullet$. It results in the movement of the Ti/f toward the Ti side. R3 corresponds to metal Ti generating $\mathrm{V}_{\mathrm{Ti}}{ }^{\prime \prime \prime}$ and $\mathrm{V}_{\mathrm{Ti}}$. R5-R8 take place at the outer layer film/solution interface ( $\mathrm{f} \mid \mathrm{s})$. R5 represents the formation of $\mathrm{V}_{\mathrm{Ti}}{ }^{\prime \prime \prime}$ and $\mathrm{Ti}\left(\mathrm{H}_{2} \mathrm{O}\right)_{\mathrm{n}}{ }^{4+}$, which are soluble. $\mathrm{V}_{\mathrm{Ti}}{ }^{\prime \prime \prime}$ is transferred by the electric field toward the Ti I $\mathrm{f}$ where they are annihilated towards the Ti side (R1). R6 indicates the absorption of $\mathrm{O}^{2-}$ into $\mathrm{V}_{\mathrm{O}}{ }^{\bullet \bullet}$ resulting in $\mathrm{O}_{\mathrm{O}}$. $\mathrm{R} 7$ represents the dissolution of the oxide film. In addition, the dissolution of the oxide film is necessary for the oxide film to attain steady-state. Cation-vacancy annihilation (via $\mathrm{R} 4$ ) leads to $\mathrm{V}_{\mathrm{O}} \bullet \bullet / \mathrm{V}_{\mathrm{Ti}}{ }^{\prime \prime \prime}$ interactions, which are driven by the electrostatic attraction between high concentrations of oppositely charged defects [59]. R9 corresponds to the oxygen evolution reaction.

The addition of $\mathrm{R} 1$ and $\mathrm{R} 5$ or $\mathrm{R} 2$ and $\mathrm{R} 6$ result in the $\mathrm{Ti}_{\mathrm{i}}{ }^{\bullet \bullet \bullet \bullet}$ and $\mathrm{V}_{\mathrm{Ti}}{ }^{\prime \prime \prime}$ eliminated, yields:

$$
\mathrm{Ti} \rightarrow \mathrm{Ti}^{4+}(a q)+v_{\mathrm{Ti}}+4 \mathrm{e}^{-}
$$

which indicates metal Ti dissolution. The barrier inner layer is a semi-permeable membrane [54]. The addition of $\mathrm{R} 3$ and $\mathrm{R} 8$, result in the oxygen vacancy eliminated, yields:

$$
\mathrm{Ti}+\chi \mathrm{H}_{2} \mathrm{O} \rightarrow \mathrm{Ti}_{\mathrm{Ti}}+\chi \mathrm{O}_{\mathrm{O}}+\mathrm{e}^{-}
$$

which corresponds to the growth of the barrier layer. $\mathrm{V}_{\mathrm{O}} \bullet \bullet$ generated at $\mathrm{f} / \mathrm{s}$ via $\mathrm{R} 2$ and annihilated at $\mathrm{Ti} / \mathrm{f}$ via R6. By means of hopping mechanism, the $\mathrm{O}_{\mathrm{O}}$ ions are transferred through $\mathrm{V}_{\mathrm{O}}{ }^{\bullet \bullet}$ toward the $\mathrm{Ti} / \mathrm{f}$. Meanwhile, $\mathrm{V}_{\mathrm{O}} \bullet \bullet$ is transferred towards the $\mathrm{f} / \mathrm{s}$ via the electric field and the concentration gradient [54], which determines barrier layer growth towards into the metal. The species in the solution does not participate in the growth of the barrier layer. This result is in accordance with the XPS results that the barrier layer contains only Ti and O elements. The outer layer forms by the hydrolysis of $\mathrm{H}_{2} \mathrm{O}$. As a result, the outer layer comprises oxide, hydroxide and hydrated oxide. The growth rate of the anodic oxide film is related to the concentration of oxygen vacancies which depends on applied potential [3]. Therefore, the higher the anodic potential, the thicker film oxide film thickness.

The crystallization stage of anodic titanium oxide films under different potentials are shown in Figure 11. As mentioned by other research [60,61], the crystallization of the of anodic oxide film is considered to be a thermally-induced, slow evolving process, and promoted by enhancing the oxide potential. 
For $\mathrm{Ti}_{10}$ sample, at the end of grown stage, the current density is relatively small, the film crystallization occurs at a very slow speed, numerous micro-crystals randomly emerge at the beginning of titanium anodization and grow to small crystalline grains in the following process. For the $\mathrm{Ti}_{30}$ sample, the current density is relatively large, the oxygen bubbles are formed and released from the surface due to the OER, and the films breakdown is enhanced. As reported by Dyer et al. [62], crystallization is promoted by breakdown of amorphous anodic oxide films because the breakdown can enhance the local current density. As a result, numerous of $\mathrm{TiO}_{2}$ micro-crystals grow quickly, and form bigger crystalline grains. When the titanium treated at $50 \mathrm{~V}$, at the end of the grown stage, the current density is very large and the OER is very high frequency. Therefore, the micro-crystals are quickly formed. With the anodizing time prolonged, these micro-crystals join together and form a smooth region.

\section{Conclusions}

The effect of anodic potential on passive films in $0.5 \mathrm{M} \mathrm{H}_{2} \mathrm{SO}_{4}$ solution has been investigated using SEM, AFM, XPS, potentiodynamic polarization curves and EIS.

The SEM and AFM results show that the anodic potential has a positive effect on the characteristics of the passive film. With increasing anodic potential, the surface micromorphology became more compact and lower roughness. XPS analysis revealed that the thickness of the anodic oxide film increases with increasing anodic potential. The potentiodynamic polarization curves revealed that the $\mathrm{E}_{\text {corr }}$ shifted towards more positive values and corrosion current density $j_{\text {corr }}$ values decreased with increasing anodic potential.

Author Contributions: Conceptualization, L.Z. and T.F.; methodology, Y.D.; software, R.G.; validation, D.T.; formal analysis, L.Z.; investigation, T.F.; resources, L.Z.; data curation, K.W.; writing-original draft preparation, L.Z.; writing—review and editing, T.F.; visualization, D.T.; supervision, J.Y.; project administration, L.Z. and R.G.; funding acquisition, L.Z.

Funding: Science and Technology Project of Yunnan Province (Preparation and application of plateau characteristic plants based semicarbonized functional materials and fragrance); Foundational Project of China Tabacco Yunnan Industrial Co., Ltd. (2015CP02, 2015CP03); Technological Innovation Talent Project of Yunnan Province (2016HB009).

Conflicts of Interest: The authors declare no conflict of interest.

\section{References}

1. Diamanti, M.V.; Pedeferri, M.P. Effect of anodic oxidation parameters on the titanium oxides formation. Corros. Sci. 2007, 49, 939-948. [CrossRef]

2. Oliveira, V.M.C.A.; Aguiar, C.; Vazquez, A.M.; Robin, A.; Barboza, M.J.R. Improving corrosion resistance of Ti-6Al-4V alloy through plasma-assisted PVD deposited nitride coatings. Corros. Sci. 2014, 88, 317-327. [CrossRef]

3. Jiang, Z.; Dai, X.; Norby, T.; Middleton, H. Investigation of pitting resistance of titanium based on a modified point defect model. Corros. Sci. 2011, 53, 815-821. [CrossRef]

4. Li, S.; Yao, W.; Liu, J.; Yu, M.; Wu, L.; Ma, K. Study on anodic oxidation process and property of composite film formed on Ti-10V-2Fe-3Al alloy in SiC nanoparticle suspension. Surf. Coat. Technol. 2015, 277, $234-241$. [CrossRef]

5. Hanawa, T. Metal ion release from metal implants. Mater. Sci. Eng. C 2004, 24, 745-752. [CrossRef]

6. Jiang, Z.; Norby, T.; Middleton, H. Evaluation of metastable pitting on titanium by charge integration of current transients. Corros. Sci. 2010, 52, 3158-3161. [CrossRef]

7. Manhabosco, T.M.; Tamborim, S.M.; Santos, C.B.D.; Müller, I.L. Tribological, electrochemical and tribo-electrochemical characterization of bare and nitrided Ti6Al4V in simulated body fluid solution. Corros. Sci. 2011, 53, 1786-1793. [CrossRef]

8. Wang, J.; Ma, Y.; Guan, J.; Zhang, D. Characterizations of anodic oxide films formed on Ti6Al4V in the silicate electrolyte with sodium polyacrylate as an additive. Surf. Coat. Technol. 2018, 338, 14-21. [CrossRef] 
9. Narayanan, R.; Seshadri, S.K. Phosphoric acid anodization of Ti-6Al-4V-Structural and corrosion aspects. Corros. Sci. 2007, 49, 542-558. [CrossRef]

10. Karambakhsh, A.; Afshar, A.; Ghahramani, S.; Malekinejad, P. Pure Commercial Titanium Color Anodizing and Corrosion Resistance. J. Mater. Eng. Perform. 2011, 20, 1690-1696. [CrossRef]

11. Simka, W.; Sadkowski, A.; Warczak, M.; Iwaniak, A.; Dercz, G.; Michalska, J.; Maciej, A. Characterization of passive films formed on titanium during anodic oxidation. Electrochim. Acta 2011, 56, 8962-8968. [CrossRef]

12. Xing, J.H.; Xia, Z.B.; Hui, L.I.; Wang, Y.Y.; Zhong, L. Growth and crystallization behaviors of anodic oxide films on sputter-deposited titanium at very low potentials. Trans. Nonferrous Met. Soc. China 2013, 23, 3286-3292. [CrossRef]

13. Kuromoto, N.K.; Simão, R.A.; Soares, G.A. Titanium oxide films produced on commercially pure titanium by anodic oxidation with different voltages. Mater. Charact. 2007, 58, 114-121. [CrossRef]

14. Nanjo, H.; Deng, H.; Oconer, I.S.; Ishikawa, I.; Suzuki, T.M. Effect of Ultraviolet Light Irradiation on Structure and Electrochemical Properties of Iron Surface. Jpn. J. Appl. Phys. 2005, 44, 539-542. [CrossRef]

15. Sivakumar, B.; Pathak, L.C.; Singh, R. Role of surface roughness on corrosion and fretting corrosion behaviour of commercially pure titanium in Ringer's solution for bio-implant application. Appl. Surf. Sci. 2017, 401, 385-398. [CrossRef]

16. Xia, Z.; Nanjo, H.; Aizawa, T.; Kanakubo, M.; Fujimura, M.; Onagawa, J. Growth process of atomically flat anodic films on titanium under potentiostatical electrochemical treatment in $\mathrm{H}_{2} \mathrm{SO}_{4}$ solution. Surf. Sci. 2007, 601, 5133-5141. [CrossRef]

17. Xing, J.H.; Xia, Z.B.; Hu, J.F.; Zhang, Y.H.; Zhong, L. Growth and Crystallization of Titanium Oxide Films at Different Anodization Modes. J. Electrochem. Soc. 2013, 160, C239-C246. [CrossRef]

18. Delplancke, J.L.; Garnier, A.; Massiani, Y.; Winand, R. Influence of the anodizing procedure on the structure and the properties of titanium oxide films and its effect on copper nucleation. J. Appl. Polym. Sci. 1994, 39, 1281-1289. [CrossRef]

19. Kudelka, S.; Michaelis, A.; Schultze, J.W. Effect of texture and formation rate on ionic and electronic properties of passive layers on Ti single crystals. Electrochim. Acta 1996, 41, 863-870. [CrossRef]

20. Alves, A.; Wenger, F.; Ponthiaux, P.; Celis, J.-P.; Pinto, A.; Rocha, L.; Fernandes, J. Corrosion mechanisms in titanium oxide-based films produced by anodic treatment. Electrochim. Acta 2017, 234, 16-27. [CrossRef]

21. Mu, S.; Li, N.; Li, D.; Zou, Z. Investigation of a transparent chromate (III) passive film on electroless Ni-P coating by XPS and electrochemical methods. Electrochim. Acta 2009, 54, 6718-6724. [CrossRef]

22. Komatsu, I.; Aoki, H.; Ebisawa, M.; Kuroda, A.; Kuroda, K.; Maeda, S. Color change mechanism of niobium oxide thin film with incidental light angle and applied voltage. Thin Solid Film. 2016, 603, 180-186. [CrossRef]

23. Xing, J.; Xia, Z.; Hu, J.; Zhang, Y.; Zhong, L. Time dependence of growth and crystallization of anodic titanium oxide films in potentiostatic mode. Corros. Sci. 2013, 75, 212-219. [CrossRef]

24. Matykina, E.; Arrabal, R.; Skeldon, P.; Thompson, G.E.; Habazaki, H. Influence of grain orientation on oxygen generation in anodic titania. Thin Solid Film. 2008, 516, 2296-2305. [CrossRef]

25. Benea, L.; Danaila, E.; Ponthiaux, P. Effect of titania anodic formation and hydroxyapatite electrodeposition on electrochemical behaviour of Ti-6Al-4V alloy under fretting conditions for biomedical applications. Corros. Sci. 2015, 91, 262-271. [CrossRef]

26. Elias, C.N.; Oshida, Y.; Lima, J.H.C.; Muller, C.A. Relationship between surface properties (roughness, wettability and morphology) of titanium and dental implant removal torque. J. Mech. Behav. Biomed. Mater. 2008, 1, 234. [CrossRef] [PubMed]

27. Ohtsuka, T.; Guo, J.; Sato, N. ChemInform Abstract: Raman Spectra of the Anodic Oxide Film on Titanium in Acidic Sulfate and Neutral Phosphate Solutions. Cheminform 1987, 18, 2473-2476. [CrossRef]

28. Si, H.Y.; Sun, Z.H.; Kang, X.; Zi, W.W.; Zhang, H.L. Voltage-dependent morphology, wettability and photocurrent response of anodic porous titanium dioxide films. Microporous Mesoporous Mater. 2009, 119, 75-81. [CrossRef]

29. Fattah-Alhosseini, A. Passivity of AISI 321 stainless steel in $0.5 \mathrm{M} \mathrm{H}_{2} \mathrm{SO}_{4}$ solution studied by Mott-Schottky analysis in conjunction with the point defect model. Arab. J. Chem. 2016, 9, S1342-S1348. [CrossRef]

30. Wang, C.; Pan, L.; Zhang, Y.; Xiao, S.; Chen, Y. Deoxidization mechanism of hydrogen in $\mathrm{TiH}_{2}$ dehydrogenation process. Int. J. Hydrogen Energy 2016, 41, 14836-14841. [CrossRef]

31. Jiang, Z.; Dai, X.; Middleton, H. Effect of silicon on corrosion resistance of Ti-Si alloys. Mater. Sci. Eng. B 2011, 176, 79-86. [CrossRef] 
32. Tsutsumi, Y.; Nishimura, D.; Doi, H.; Nomura, N.; Hanawa, T. Difference in surface reactions between titanium and zirconium in Hanks' solution to elucidate mechanism of calcium phosphate formation on titanium using XPS and cathodic polarization. Mater. Sci. Eng. B 2009, 29, 1702-1708. [CrossRef]

33. Vesel, A.; Mozetic, M.; Drenik, A.; Hauptman, N.; Balat-Pichelin, M. High temperature oxidation of stainless steel AISI316L in air plasma. Appl. Surf. Sci. 2008, 255, 1759-1765. [CrossRef]

34. Gui, Y.; Meng, X.B.; Zheng, Z.J.; Gao, Y. Critical temperature determination of detectable Cr diffusion enhancement by nanostructure through structural evolution analysis of the oxide films at $25-450{ }^{\circ} \mathrm{C}$ on 304 stainless steel. Appl. Surf. Sci. 2017, 419, 512-521. [CrossRef]

35. Kirchheim, R. Growth kinetics of passive films. Electrochim. Acta 1987, 32, 1619-1629. [CrossRef]

36. Krawiec, H.; Vignal, V.; Schwarzenboeck, E.; Banas, J. Role of plastic deformation and microstructure in the micro-electrochemical behaviour of Ti-6Al-4V in sodium chloride solution. Electrochim. Acta 2013, 104, 400-406. [CrossRef]

37. Mccafferty, E. Validation of corrosion rates measured by the Tafel extrapolation method. Corros. Sci. 2005, 47, 3202-3215. [CrossRef]

38. Poorqasemi, E.; Abootalebi, O.; Peikari, M.; Haqdar, F. Investigating accuracy of the Tafel extrapolation method in $\mathrm{HCl}$ solutions. Corros. Sci. 2009, 51, 1043-1054. [CrossRef]

39. Kelly, E.J. Electrochemical Behavior of Titanium; Springer: New York, NY, USA, 1982.

40. Fu, T.; Zhan, Z.; Zhang, L.; Yang, Y.; Liu, Z.; Liu, J.; Li, L.; Yu, X. Effect of surface mechanical attrition treatment on corrosion resistance of commercial pure titanium. Surf. Coat. Technol. 2015, 280, 129-135. [CrossRef]

41. Hernández-López, J.M.; Conde, A.; Damborenea, J.J.D.; Arenas, M.A. Electrochemical response of $\mathrm{TiO}_{2}$ anodic layers fabricated on Ti6A14V alloy with nanoporous, dual and nanotubular morphology. Corros. Sci. 2016, 112, 194-203. [CrossRef]

42. Ningshen, S.; Mudali, U.K.; Ramya, S.; Raj, B. Corrosion behaviour of AISI type 304L stainless steel in nitric acid media containing oxidizing species. Corros. Sci. 2011, 53, 64-70. [CrossRef]

43. Robin, A.; Meirelis, J.P. Influence of fluoride concentration and $\mathrm{pH}$ on corrosion behavior of Ti-6Al-4V and Ti-23Ta alloys in artificial saliva. Mater. Corros. 2015, 58, 173-180. [CrossRef]

44. Ter-Ovanessian, B.; Alemany-Dumont, C.; Normand, B. Electronic and transport properties of passive films grown on different Ni-Cr binary alloys in relation to the pitting susceptibility. Electrochim. Acta 2014, 133, 373-381. [CrossRef]

45. Xu, J.; Liu, L.; Li, Z.; Munroe, P.; Xie, Z.H. Niobium addition enhancing the corrosion resistance of nanocrystalline $\mathrm{Ti}_{5} \mathrm{Si}_{3}$ coating in $\mathrm{H}_{2} \mathrm{SO}_{4}$ solution. Acta Mater. 2014, 63, 245-260. [CrossRef]

46. Jurczakowski, R.; Hitz, C.; Lasia, A. Impedance of porous Au based electrodes. J. Electroanal. Chem. 2004, 572, 355-366. [CrossRef]

47. Leiva-García, R.; Fernandes, J.C.S.; Muñoz-Portero, M.J.; García-Antón, J. Study of the sensitisation process of a duplex stainless steel (UNS 1.4462) by means of confocal microscopy and localised electrochemical techniques. Corros. Sci. 2015, 94, 327-341.

48. Orazem, M.E.; PéBèRe, N.; Tribollet, B. Enhanced Graphical Representation of Electrochemical Impedance Data. J. Electrochem. Soc. 2006, 153, B129-B36. [CrossRef]

49. Mantzila, A.G.; Prodromidis, M.I. Development and study of anodic Ti/TiO electrodes and their potential use as impedimetric immunosensors. Electrochim. Acta 2006, 51, 3537-3542. [CrossRef]

50. Busani, T.; Devine, R.A.B. Dielectric and infrared properties of $\mathrm{TiO}_{2}$ films containing anatase and rutile. Semicond. Sci. Technol. 2005, 20, 870. [CrossRef]

51. Habazaki, H.; Uozumi, M.; Konno, H.; Shimizu, K.; Skeldon, P.; Thompson, G.E. Crystallization of anodic titania on titanium and its alloys. Corros. Sci. 2003, 45, 2063-2073. [CrossRef]

52. Hwang, B.J.; Hwang, J.R. Kinetic model of anodic oxidation of titanium in sulphuric acid. J. Appl. Electrochem. 1993, 23, 1056-1062. [CrossRef]

53. Fu, T.; Wang, X.; Liu, J.; Li, L.; Yu, X.; Zhan, Z. Characteristics and Corrosion Behavior of Pure Titanium Subjected to Surface Mechanical Attrition. JOM 2017, 69, 1-4. [CrossRef]

54. Jiang, Z.; Dai, X.; Middleton, H. Investigation on passivity of titanium under steady-state conditions in acidic solutions. Mater. Chem. Phys. 2011, 126, 859-865. [CrossRef] 
55. Kong, D.-S.; Lu, W.-H.; Yu, Z.-Y.; Wu, J.-X.; Fan, W.-J.; Liu, H.-Y.; Feng, Y.-Y. Studying on the Point-Defect-Conductive Property of the Semiconducting Anodic Oxide Films on Titanium. J. Electrochem. Soc. 2009, 156, C39-C44. [CrossRef]

56. Veluchamy, A.; Sherwood, D.; Emmanuel, B.; Cole, I.S. Critical review on the passive film formation and breakdown on iron electrode and the models for the mechanisms underlying passivity. J. Electroanal. Chem. 2017, 785, 196-215. [CrossRef]

57. Macdonald, D.D. The history of the Point Defect Model for the passive state: A brief review of film growth aspects. Electrochim. Acta 2011, 56, 1761-1772. [CrossRef]

58. Xia, D.-H.X.; Song, S.; Zhu, R.; Behnamian, Y.; Shen, C.; Wang, J.; Luo, J.; Lu, Y.; Klimas, S. A mechanistic study on thiosulfate-enhanced passivity degradation of Alloy 800 in chloride solutions. Electrochim. Acta 2013, 111, 510-525. [CrossRef]

59. Fernández-Domene, R.M.; Blasco-Tamarit, E.; García-García, D.M.; García-Antón, J. Passive and transpassive behaviour of Alloy 31 in a heavy brine LiBr solution. Electrochim. Acta 2013, 95, 1-11. [CrossRef]

60. Vanhumbeeck, J.F.; Ryelandt, L.; Proost, J. On the relationship between local voltage maxima and efficiency changes during galvanostatic Ti anodising. Electrochim. Acta 2009, 54, 3330-3338. [CrossRef]

61. Leach, J.S.L.; Pearson, B.R. ChemInform Abstract: Crystallization in Anodic Oxide Films. Cheminform 1988. [CrossRef]

62. Dyer, C.K.; Leach, J.S.L. ChemInform Abstract: Breakdown and Efficiency of Anodic Oxide Growth on Titanium. Chem. Inf. 1978, 9, 1032-1038. [CrossRef]

(C) 2019 by the authors. Licensee MDPI, Basel, Switzerland. This article is an open access article distributed under the terms and conditions of the Creative Commons Attribution (CC BY) license (http:/ / creativecommons.org/licenses/by/4.0/). 